\title{
Demographic characterization and social patterns of the Neotropical pampas deer
}

\author{
Mariana Cosse* and Susana González
}

\begin{abstract}
The most endangered subspecies of pampas deer Ozotoceros bezoarticus uruguayensis is an endemic cervidae of the Uruguayan temperate grasslands. The aim of our study was to assess the demographic trends, grouping structure and dynamic of this small and isolated population. We surveyed the population during seven years and detected an average of 117 ( +72.7 SD) individuals (44 censuses). The average population structure observed was $55 \%$ adult females, 34\% adult males, $10 \%$ juveniles, and 1\% fawns, with a low recruitment rate of 0.11 . The pampas deer is a gregarious cervidae with $62 \%$ of individuals being observed within groups of at least three animals. Nevertheless we observed substantial differences on group size and composition based on sex, reproductive status, season and trophic resources availability. The population dynamics showed significant changes around the year in the sexual aggregation-segregation pattern, corresponding with reproductive and physiological status. The mean density on this population $\left(11 \mathrm{deer} / \mathrm{km}^{2}\right.$ ) is the highest reported for the species. Comparable data, from other populations, showed a significant correlation between density and sex ratio, with a reduction in the proportion of males with higher deer densities. An action plan for this endangered population should include initiatives involving private landowners, and guidelines to improve the deer habitat.
\end{abstract}

Keywords: Ozotoceros bezoarticus, Population dynamics, Sexual aggregation-segregation pattern, Ungulates, Conservation, Uruguay

\section{Introduction}

The pampas deer, Ozotoceros bezoarticus (Linnaeus 1758), is an ungulate native to the open grassland habitats of South America, from $5^{\circ}$ to $41^{\circ} \mathrm{S}$ (Cabrera, 1943, Jackson \& Langguth, 1987, González et al., 2010). Over the last two centuries its natural habitats (the Pampas, Cerrado, and grasslands of Argentina, Uruguay, Paraguay, Bolivia, and southern Brazil) have been drastically modified by agricultural activities (Fonseca et al., 1999, González et al., 2010). The pampas deer have been deeply affected by habitat alteration and fragmentation, which are considered to be one of the main causes of the reduction and populations decline in the species' range (González et al., 1998). This process is clearly visible in Uruguay, which is home to two endemic subspecies: $O$. $b$. arerunguaensis, represented by a population of around 1000 individuals in El Tapado (northern Uruguay); and O. b. uruguayensis, with less than 350

\footnotetext{
* Correspondence: mcosse@iibce.edu.uy

Genética de la Conservación, Departamento de Genética, IIBCE-Facultad de Ciencias/UdelaR, Av. Italia 3318, 11600, Montevideo, Uruguay
}

individuals, located at Los Ajos in southeast Uruguay (González et al., 2002). While populations of the other subspecies (O. b. leucogaster, O. b. bezoarticus, and $O . b$. celer) are found in protected areas in Argentina, Bolivia, and Brazil, the Uruguayan populations are located exclusively on private land where several agricultural activities are conducted (Jackson et al., 1980, Cosse et al., 2009, González et al., 2010).

An understanding of the spatial relationships between species and their environments is essential to prioritize research and conservation needs. Group structure is shaped by feeding and anti-predatory strategies (Caughley, 1964). Group foraging generally entails costs and benefits for the individuals, associated with the presence of other individuals of the same species (Krause \& Ruxton, 2002). Determining a population's grouping strategy and its variation in different environments can provide information on various aspects, such as quality of the environment and hunting pressure (Morrison et al., 2006).

\section{实 Springer}


In most social ungulate species, males and females live in separate groups outside the breeding season, usually using different home ranges, or different kinds of habitats (Clutton-Brock et al., 1982). Ruckstuhl (2007) provides a comprehensive review of the hypotheses proposed to explain sexual segregation among ungulates. Comprehension these processes in pampas deer is key for understanding the mechanisms that shape the genetic structure of the populations and the implications of the habitat they occupy for the degree of genetic variability and management options.

Previous observations made in several populations showed pampas deer living in small herds, with a group size of one to twelve, but rarely more than five or six animals (Fitzroy \& Darwin, 1839, Cabrera et al., 1940, Merino \& Beccaceci, 1999, Eisenberg, 2000, Mourão et al., 2000, Dellafiore et al., 2003, Pereira et al., 2005). According to Jackson \& Langguth (1987) wild herds are dynamic in size and composition. Especially the males, move from one group to another, but mother-young bonds appear to be strong with fawns staying with their mother until they are at least one year old. However the dynamics of the Pampas deer group composition in agro-ecosystems has not been systematically studied.

The aim of our study was to document the group structure, demography and sex segregation behavior on an isolated pampas deer population in Uruguay. We estimated the population's size to evaluate the population trend; and we assessed the seasonal variations on group's conformation. Furthermore, we examined whether mean group size was linked to population density. At the same time, we determined if there are differences in the type of group (nursery/bachelor groups or mixed group) chosen by an individual deer based on deer sex or reproductive status. We examined whether sexual segregation and aggregation within the population was related to life cycle.

\section{Methods}

\section{Study area and animals}

The study area is mainly located in an $80 \mathrm{~km}^{2}$ ranch $\left(33^{\circ}\right.$ $50^{\prime} 01^{\prime \prime}$ S; 54 01' 34" W) within the "Bañados del Este" Biosphere Reserve at Ramsar Area, in the southeastern Uruguayan Department of Rocha. The landscape is characterized by low, rolling hills; the parent material consists of Quaternary unconsolidated sediments (clays, argillaceous mud, and sands and, locally in rocky points, igneous or metamorphic rocks). The soils are predominantly gley soils. Altitudes range from -5 to 100 masl, the annual average rainfall is $1000 \mathrm{~mm}$ and the average annual temperature is $16^{\circ} \mathrm{C}$ (Cosse et al., 2009). The main land use activities are livestock (cattle and sheep) ranching, agricultural crops (rice, soy, wheat) and pasture (ryegrass). The pampas deer are free ranging in this complex landscape of discrete patches (paddocks) and are conspicuously patchy in their distribution among paddocks. The paddocks vary on grass species and livestock load.

\section{Data recording}

We conducted fieldwork seasonally over the course of seven years, from 1996 to 1999 and 2002 to 2004. Both surveyed periods were assembled previously we performed a Homogeneity of Variances Analysis to perform the demographic calculations.

Observations were made early in the morning from a vehicle traveling at a slow constant speed through a fixed $8 \mathrm{~km}$ route, with surveys averaging three hours in duration We performed the observations using a $10 \times 40$ telescope and at distances of up to $500 \mathrm{~m}$. We estimated Herd Composition Count (HCC) (Kaji et al., 2005). For each survey, we recorded the mean group size and group composition. We defined the groups as singletons (adult male, adult female), bachelor groups (only males), nursery groups (including females and sub-adults/juveniles of unknown sex) and mixed-sex groups. The two sexes were identified based on the presence or absence of antlers, and the year's offspring were distinguished from older animals on the basis of body size. In cases where sex or group composition could not be determined reliably, data was excluded from the analysis. Monthly observations were pooled as seasonal observations as follows: 1: summer; 2: autumn; 3: winter and 4: spring.

We estimated the typical group size (TGS) following Jarman (1974) and Moore (2001):

$$
T G S=\frac{\sum_{i=1}^{N} n_{i}^{2}}{\sum_{i=1}^{N} n_{i}}
$$

Where $n_{i}$ is the number in each group ${ }_{i}$ and $N$ is the total number of groups observed (Jarman, 1974). This parameter provided information on the size of the group observed for an average individual.

In the mixed-sex groups with three or more individuals (with no unidentified individuals) the sex ratio (number of males/number of females) and juvenile ratio (number of juveniles/total group size) were determined. For each census we analyzed the proportion of each category of individuals in every group type. We used the Kruskal-Wallis (KW) variance analysis to test the differences between variables (Zar, 1999). We run an $r x c$ contingency test (Milton \& Tsokos, 1987) to analyze the difference in the type of association (singletons, mixedsex groups, single-sex groups) presented by individuals based on their sex. The contingency table was run on online software Statistics to Use (Kirkman, 1996). 


\section{Density}

The pampas deer in Los Ajos are conspicuously patchy in their distribution among paddocks. We estimate two densities values: i) the mean global density, corresponding with the number of deer surveyed on total area they occupy; ii) the mean density only on occupied paddocks, to estimate the deer load on the pastures we calculated the deer density based on the number of individuals per paddock (area) for each survey. We correlated the mean group size and density per paddock and year.

\section{Population viability analysis}

We examined the complex interactions between pampas deer demography, environmental and genetic factors by computer simulation modeling, using the program VORTEX version 9.5. VORTEX has been widely used in several endangered species and is especially powerful for modeling vertebrate wildlife population behavior (Lacy et al. 2009).

The program yields the following information: probability of persistence of the population, for a maximum population size (Nmax); the expected persistence time, will depend on the average growth rate $r\left(\mathrm{r}=\mathrm{n}^{\circ}\right.$ births $\mathrm{n}^{\circ}$ deaths) as well as the variance of this parameter due to environmental fluctuations; size of the average population along time; expected and observed average heterozygosity; average number of alleles; final allele composition of the population; population growth rate (stochastic and deterministic r); probability of extinction is defined as the absence of any of the sexes.

We considered the data from the population structure observed in the surveyed years (sex ratio and age structure), and also the data of the sample of animals captured (González \& Duarte, 2003). The variables used were: size of the initial population, one basic scenario was performed, with an initial population size 400, based in current data; for the 400 individual population, age and sex classes were calculated in proportion to the real distribution; during simulations VORTEX distributes the age-sex structure according to the reproduction and death rates specified in each scenario, using the deterministic algorithms of Leslies' matrix. We run 200 iterations, for 350 years. Results were summarized every ten years.

One basic scenario was considered, with a carrying capacity of the environment (K) of 600 (s.d. 50) individuals. VORTEX fixes carrying capacity as an upper limit for population size, beyond which an additional mortality rate is imposed, proportional along all age-sex classes in order to return the population to the specified $K$ value. Migration and supplementation were not considered. Reproductive system variables considered: polygyny mating system; 18 month of age of reproductive maturity of females and 2 years of males; maximum breeding age (senescence) of 6 years for both sexes; sex ratio at birth 50\%; average litter size of 1 ; proportion of adult females in the breeding pool per year was of $85 \%$ (s.d.: $5 \%$ ) and for adult males was $90 \%$ and successfully siring $72 \%$; non inbreeding was considered in the modeling.

The annual mortality rate of individuals under 1 year old of age for females was considered: $32 \%$ (s.d. $=5 \%$ ), and for males $40 \%$ (s.d. $=5 \%$ ) as a maximum value related to environmental conditions, being the first year of life the most critical in large mammals. The annual mortality rate of animals above 1 year of age is $10 \%$ (s.d. $=5 \%$ ).

\section{Sexual segregation}

We analyzed the sexual segregation or aggregation pattern using the SSAS index (Bonenfant et al., 2007). We conducted the analyses using the $\mathrm{R}$ program ( $\mathrm{R}$ Development Core Team, 2009) following the protocol developed by Bonenfant et al. (2007).

\section{Inter-population analysis}

We compared the mean group size and density reported in the literature from different populations in the species' distribution range, including information on sex ratio, latitude and longitude. A multiple regression analysis was performed to determine the best predictors of group size and the association between different variables (Zar, 1999).

\section{Results}

\section{Demographic parameters}

We conducted 44 surveys over seven years, and analyzed a total of 2149 groups. The mean population size estimation was $117(\mathrm{SD}=72.7)$. The average ratio of adult males to adult females was 0.61 . This sex ratio deviated significantly from a 1:1 ratio $\left(\chi^{2}=167.5, \mathrm{df}=1, \mathrm{p}<0.05\right)$.

The overall population structure observed was $55 \%$ adult females, $34 \%$ adult males, $10 \%$ juveniles, and $1 \%$ young. The demographic parameters estimated were: mean size of the population $\bar{x}=117$; sex and age structure: $40 \hat{\delta} \widehat{\delta}: 64$ 우 12juv.: 1fawn; mean recruitment rate $\bar{x}=0.11$; age of first reproduction; 1.5 years; litter size: 1 fawn/ $\rightarrow$.

\section{Social structure and groupings}

The mean size for the 2149 groups observed was 2.4 individuals (range 1-67; $3.56 \mathrm{SD}$ ) and the mean Typical Group Size in 44 censuses was 7.18 (range 1.9 - 37.9; 7.9 SD). We did not obtain a significant correlation between mean group sizes or mean Typical Group Size and density per enclosure, neither overall or seasonally.

When we analyzed the average annual group compositions we found that, $19 \%$ of the groups were singletons, $19 \%$ were in couples, $44 \%$ were groups of three to nine animals, and $18 \%$ were in groups of 10 or more individuals.

We recorded 175 nursery groups, with a mean 2.7 individuals (range 2-7; $1.1 \mathrm{SD}$ ). We found a significant 
variation in the size of these groups based on the season (KW: $\mathrm{GL}=3 ; \mathrm{N}=175 ; \mathrm{H}=11.02 ; \mathrm{p}=0.01$ ), whose size dropped to a minimum during birth season. In contrast, we observed no significant seasonal variation in the size of the bachelors groups $(\mathrm{N}=66$; mean size $=2.6$, range $2-7,1.2 \mathrm{SD})$. For mixed-sex groups $(\mathrm{N}=391)$ the mean size was 4.70 (range 2-67; 6.2 SD), with larger groups observed in July and August (winter) (KW: GL $=9, \mathrm{~N}=$ 391; $\mathrm{H}=25.08 \mathrm{p}=0.0029$ ) (Figure 1).

The differences in the males and females distribution on different group type (singletons; mixed-sex groups; nursery or bachelors groups) based on sex, were statistically significant $\left(\mathrm{X}^{2}=38.5 ; \mathrm{df}=2 ; \mathrm{p}<0.0001\right.$, Table 1$)$. Overall data showed similar proportions between males and females on singletons (32\% of males was singletons and $35 \%$ of females); interestingly males proportions on mixed-sex groups are higher than females, with $53 \%$ of males conforming mixed-sex groups, respect to $42 \%$ on females. In this pampas deer population, the lower proportion of individuals were on single-sex group, only $15 \%$ of the males were on bachelors groups and $23 \%$ of the females were on nursery groups respectively; these proportions change around year but in all seasons males are in higher proportions than females on mixed-sex groups. On summer most females are on singletons and their proportion on mixed-sex groups and nursery groups are similar (32 and 30 percent respectively) (Figure 2).

\section{Los Ajos population density}

The density data were obtained from 28 censuses conducted from 1998 to 2004, which provided information on the distribution of individuals in the various areas and paddocks. A total of 3290 individuals, forming 1645 groups, were recorded for this analysis. The area used by the deer was estimated to be $33.97 \mathrm{~km}^{2}$. We did not obtain significant differences in density by years or per enclosure, neither overall or seasonally. We calculated the mean global density as 3.46 (2.16 SD), however the mean pampas deer load per paddock was 11 deer per $\mathrm{km}^{2}$ (range $1.52-54.30$; $0.98 \mathrm{SD}$ ) in 110 counts.

\section{Los Ajos population viability analysis (PVA)}

The PVA showed the average population size maintain in the simulations in 291 individuals in the modeling scenarios. The probability of extinction of the population in simulated 350 years was very low 0.015. In all cases the population size increased rapidly until maximum carrying capacity is reached, in less than ten years. In our analysis the observed growth rate (r), $r$ deterministic of 0.043 and $r$ stochastic of $0.014(\mathrm{SD}=0.061)$, being always very low but positive, and was mostly affected by the high mortality rates occurred during the first year of life.

\section{Sexual segregation-aggregation analysis}

We detected two annual periods with a non-random male-female association pattern with SSAS. In March (autumn) a sexual aggregation pattern was observed, and in September and October (spring) we observed a period of sexual segregation (Figure 3).

\section{Inter-populations analysis}

We have performed comparative analyses including information for group size (mean value), density, sex ratio, latitude and longitude on different populations in Argentina, Brazil, and Uruguay (Table 2). We observed a significant correlation between sex ratio $(\mathrm{M} / \mathrm{F})$ and density $(\mathrm{N}=9$; Spearman $=-0.76 ; \mathrm{t}(\mathrm{N}-2)=-3.11 ; \mathrm{p}=0.017)$ (Figure 4).

\section{Discussion}

\section{Demographic parameters}

Our mean size for the population estimation was 117 individuals, being very small and having along the study period remarkable fluctuations (range 16-254; $73 \mathrm{SD}$ ). Furthermore the biological examination of the captured specimens (González \& Duarte, 2003) enabled to obtain valuable information in this pampas deer wildlife sample. We observed seven-year survival for the oldest male. Additionally seven from the eight females captured, were reproductively active (being pregnant or lactating, including the youngest at 18 months of age) representing $85 \%$ of the sample. The oldest female recorded in the capture had five years old and was lactating.

The parameters obtained in the PVA showed that the population is safe from the genetic and demographic factors for the next 350 years. In all the simulations we obtained very low and positive values of $r$, which shows that the population has a very low intrinsic growth potential. The carrying capacity of the environment is the main limiting factor. Increasing the habitat available will assure the persistence and expansion of the pampas deer.

This type of population structure is characteristic of "slow" life history, where the number of individuals is close to the carrying capacity, there is a strong resource selection, and a long life expectancy (Reznick et al,, 2002, Jeschke \& Kokko, 2009). Thus, population size seems to be stabilized by a structure of adult individuals and a failure to recruit young individuals. Our results were similar to those found in the Brazilian National Park Emas population, where it was estimated that adults represented 85 to $97.7 \%$ (Schaller \& Duplaix-Hall, 1975, Redford, 1987). The low recruitment of young individuals was reported to El Tapado population, which was establish to have an estimated mortality rate of 0.4 for individuals under two years of age (Moore, 2001). 

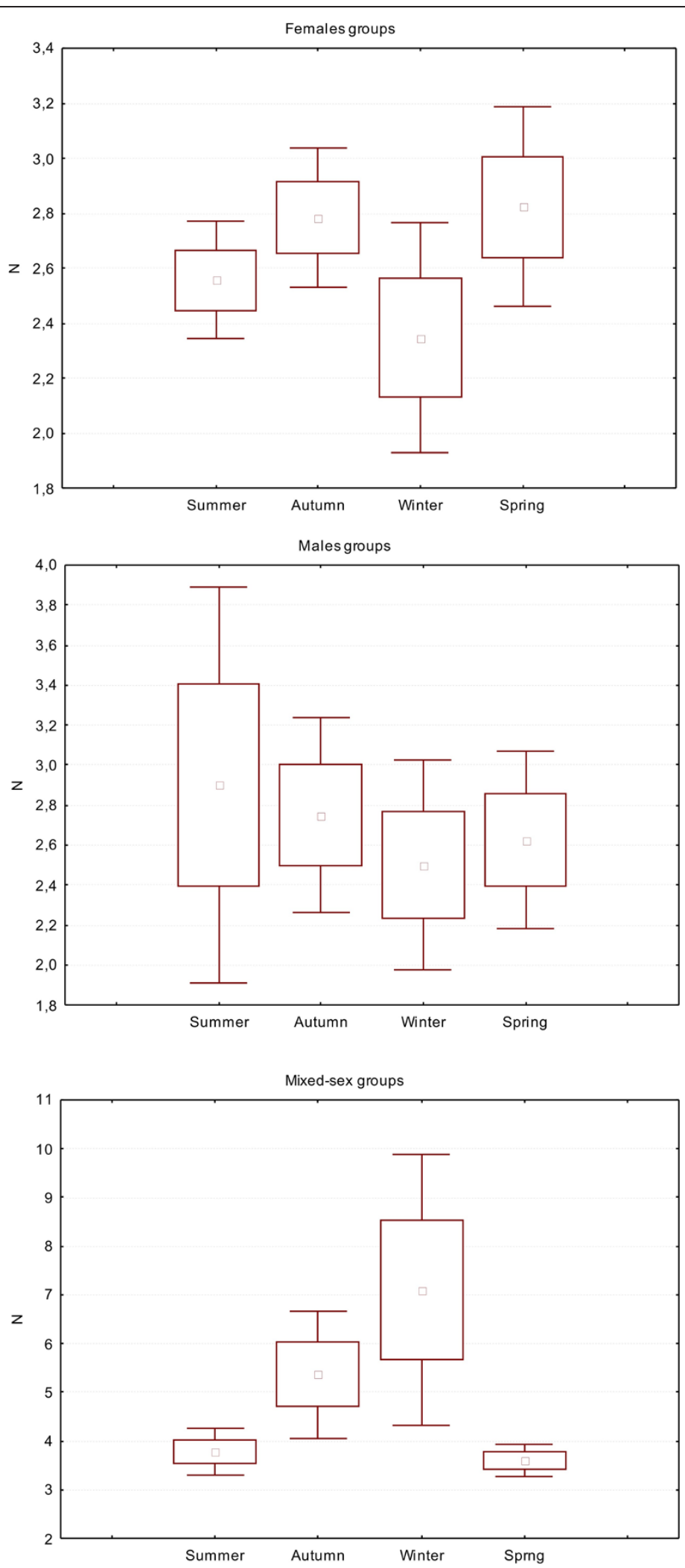

Figure 1 Mean group size $(\square)$ of females (upper), males (middle) and mixed-sex (bottom) in the different seasons. Mean \pm SE ( $\square$ ) and mean $\pm 1,96^{*} \mathrm{SE}(\mathrm{T})$. 
Table 1 Total numbers of females and males in the different type groups on the $\mathbf{4 4}$ population size estimations on seven years: single-sex groups refer to bachelor groups (males) and nursery groups (females)

\begin{tabular}{lll}
\hline Individuals & Females & Males \\
\hline Singletons & 640 & 361 \\
Mixed-sex groups & 778 & 598 \\
Single-sex groups & 420 & 173 \\
Total & 1838 & 1132 \\
\hline
\end{tabular}

We estimated the sex ratio population as 0.61 ( 1 adult male to 1.63 adult female). The birth sex ratio at Los Ajos is unknown; in captivity a 1:1 sex ratio has been recorded (Ungerfeld et al., 2008). Nevertheless these results are not generalized to the Los Ajos population, since in some ungulate species in the wild, a relationship between readily-available resources and skewed fawns sex ratio has been observed (Kruuk et al., 1999, Bonenfant et al., 2003). Also to explain the skewed sex ratio in populations it is important to consider that in other Cervidae species is common young males disperse (a behavior that entails a high energy cost and greater mortality) while females exhibited a philopatric behavior (Coulon et al., 2006, Loe et al., 2009, Clutton-Brock \& Lukas, 2012). Another explanation to this skewed ratio can be related with the agonistic behavior of males, which may increase the physiological stress (Loison et al., 1999, Pereira et al., 2006), generating individuals more sensitive to pathogens. Moreover, we observed on pampas deer populations a decline in the males proportions when population density rises (Table 2 and Figure 4). This pattern could correspond to a process where the females' density is correlated with environmental carrying capacity, while the presence of males is determined by territoriality associated with resource defense polygyny tactic (Emlen \& Oring, 1977, Vanpé et al., 2009). This tactic has been observed for various ungulate species (Dubost, 1970, Miura, 1984, Putman, 1988, Wahlstrröm, 1994). Nevertheless, the analysis in

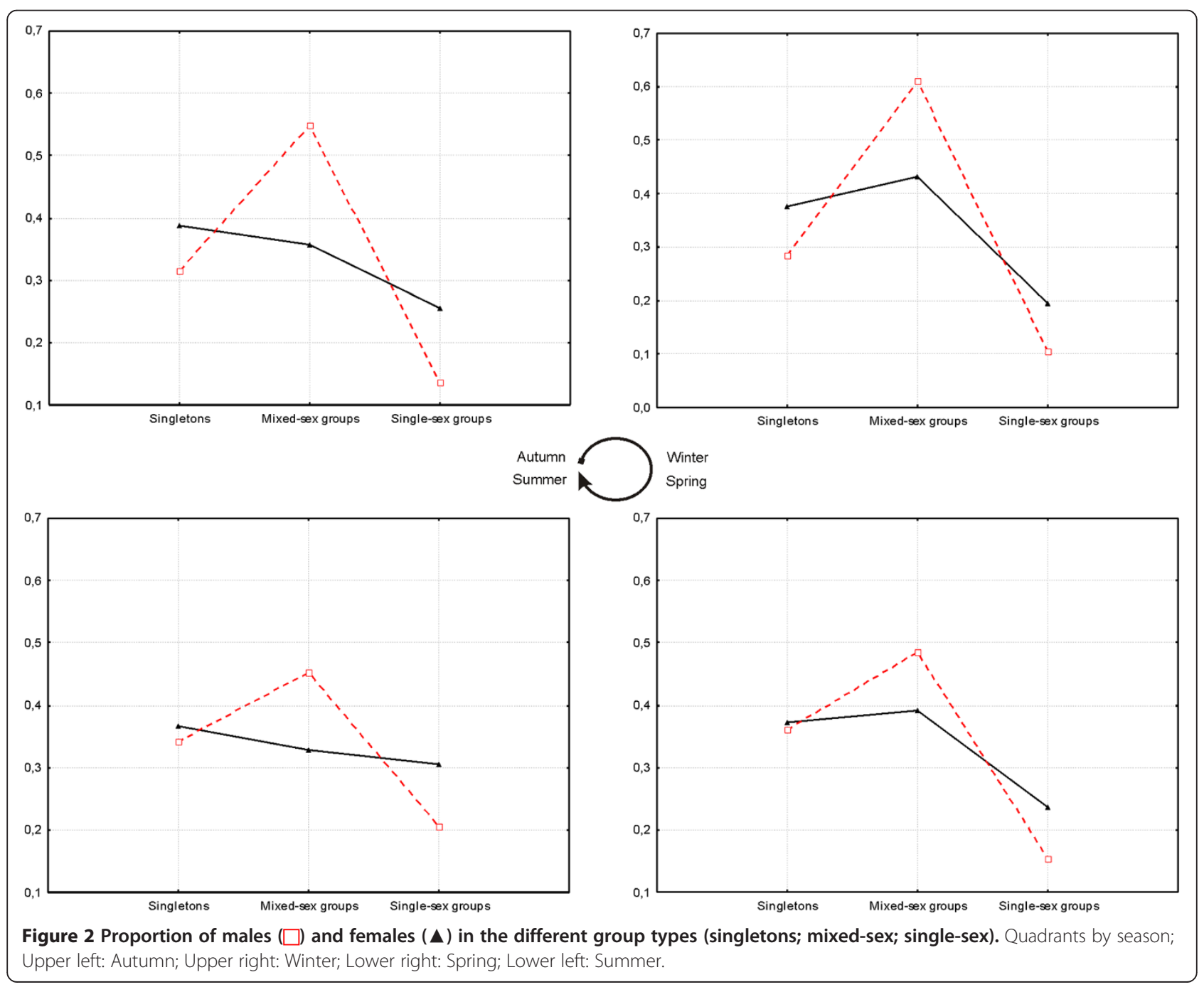




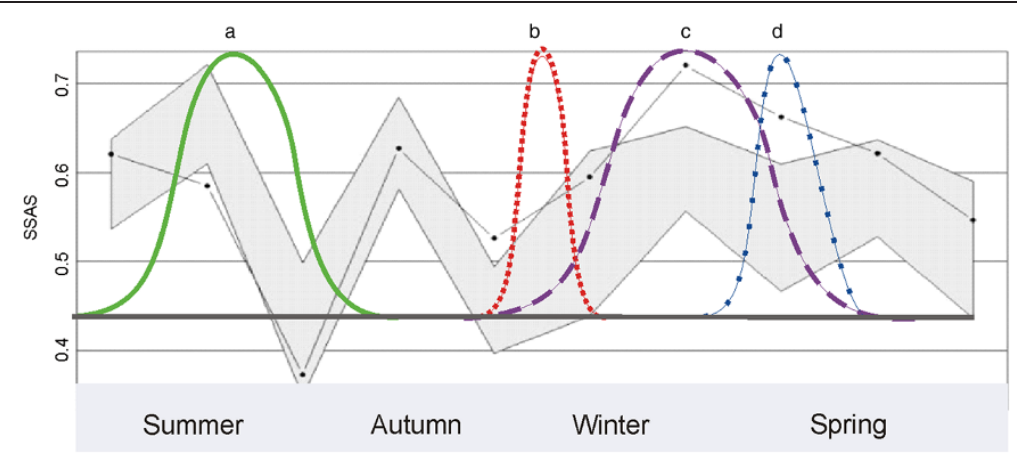

Figure 3 Results of the SASS analysis overlaying events of the biological cycle of the Pampas deer. The SSAS indicates significant sexual segregation or aggregation if the observed value (dotted line) falls above or below the shaded area (at the 5\% error level), respectively. The seasons are represented on the axial axis. The graph show the annual biology cycle of Los Ajos Pampas deer: a) unbroken curve corresponds to the mating period; b) dotted curve covers the antler shedding period; c) broken lines represent the population's birth curve; and $\mathbf{d}$ ) broken dotted line represents the antler growth period.

fecal testosterone demonstrated no significant differences in fecal testosterone concentrations among males from groups of varying sizes (Pereira et al., 2005). However, it will be need to assess the influence of resources on female distribution and their impact on male distribution and reproductive success (Vanpé et al., 2009).

\section{Social structure}

Our observations confirmed that the pampas deer is a gregarious species with $62 \%$ of the individuals in Los Ajos population within groups of at least three animals.

However the grouping structure is variable and related with several factors. The most common type of groupings we observed in the Los Ajos population were basic units of two to four individuals (41\% of the individuals) that appear to come together as feeding groups, with the largest groups forming in autumn or winter. These observations are in accordance with Pereira et al., (2005), who found large aggregations within Emas National Park population in feeding grounds such as burnt patches.

The mean group size values we observed for Los Ajos was 2.4, similar data were reported in other pampas deer populations (Redford, 1987, Merino \& Beccaceci, 1999, Netto et al., 2000, Moore, 2001, Dellafiore et al., 2003, Pereira et al., 2005, Lacerda, 2008, Pérez Carusi et al., 2009, Braga \& Kuniyoshi, 2010). The Typical Group Size (TGS) we observed at Los Ajos was 7.1 individuals, similar to the TGS (7.2 individuals) reported for the other Uruguayan population on Salto (Moore, 2001). The Uruguayan populations showed larger TGS than the recorded on Pantanal of 3.11 individuals (Lacerda, 2008). The differences between them may be due to the interaction of several factors, as carrying capacity, and including the behavior in different environments. The Uruguayan populations are mainly found in open grasslands and the Pantanal is a complex environment of open wet meadows and forested areas. Pereira et al., (2005) suggested that the low level of aggregation observed at cerrado biome is related to group instability and low density, characteristics that are also reported by Netto et al. (2000) and Jackson \& Langguth (1987). Other researchers have observed that exist, in cervidae species, an important relationship between the group size, habitat conditions and feeding style and has been

Table 2 Mean group size, density in $\mathbf{~ k m}^{2}$, and sex ratio (males/females) data for different pampas deer populations

\begin{tabular}{lllllll}
\hline Population & Author & Latitude & Longitude & Average group size & Density & Male/female \\
\hline Cerrado & Leeuwenberg \& Lara-Resende (1994) & 15.56 & 53.07 & 1.84 & 1.46 & 0.74 \\
Emas & Redford (1987) & 18.15 & 52.53 & 1.36 & 0.32 & 0.78 \\
Pantanal & Lacerda (2008) & 19.57 & 56.25 & 2.13 & 6.85 & 0.66 \\
Paraná & Braga \& Kuniyoshi (2010) & 25.34 & 49.49 & 2.29 & 1.19 & 0.83 \\
Corrientes & Merino \& Beccaceci (1999) & 28.08 & 56.33 & 1.75 & 0.39 & 0.68 \\
El Tapado & Moore (2001) & 31.36 & 56.43 & 2.20 & 7.00 & 0.67 \\
Los Ajos & Cosse et al., present work & 33.50 & 54.01 & 2.40 & 11.00 & 0.64 \\
San Luis & Dellafiore et al. (2003) & 34.22 & 65.44 & - & 0.63 & 0.76 \\
Samborombón & Giménez Dixon (1991) & 36.22 & 56.52 & 2.60 & 1.15 & 0.75 \\
\hline
\end{tabular}

The geographic location of each population (latitude-longitude) is also indicated. 
Correlation: $r=-, 7468$

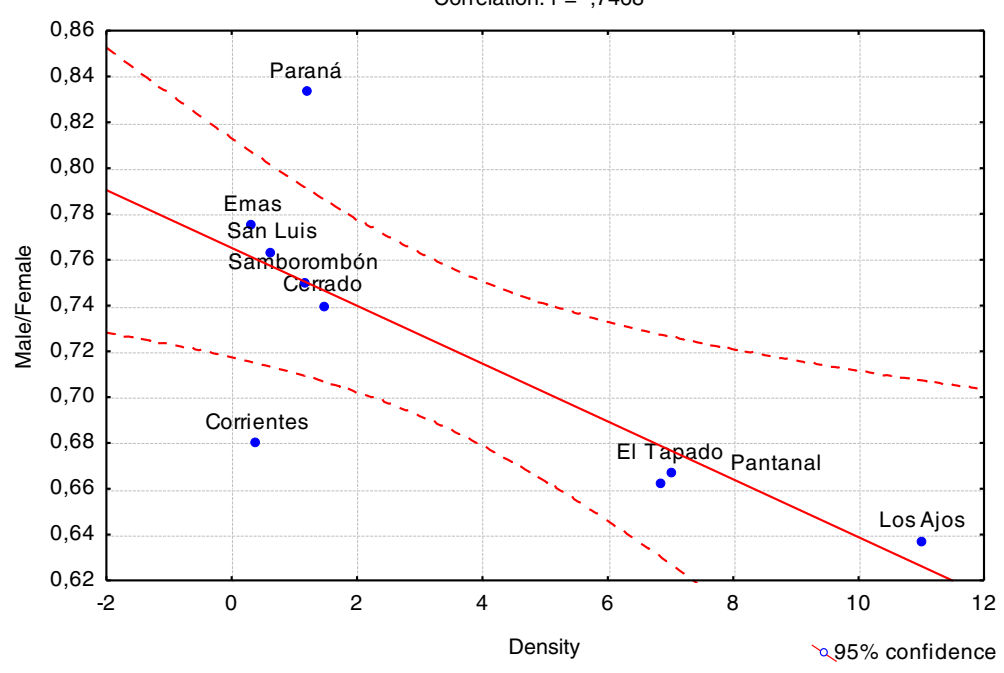

Figure 4 Correlation graphs of sex ratio (male/female) and density $\left(\mathrm{n}^{\circ} \mathrm{deer} / \mathrm{km}^{2}\right)$ for populations on the distribution range of the species.

suggested that the differences are not only among species, but also may be among populations; and individuals, which may adopt the appropriate structure for their habitat (Putman, 1988, Putman \& Flueck, 2011).

Several authors have considered the pampas deer as a "concentrate selectors" (Pinder, 1997, Rodrigues \& Monteiro-Filho, 1999), or "mixed grass feeder" (Jackson \& Giulietti, 1988, Cosse, González et al., 2009) according to Hofmann classification (Hofmann, 1989). The possible explanation to the recorded differences in feeding strategies may be also due to the phytogeographical variation throughout the pampas deer's range. The nutritional value of Uruguayan and Argentinean temperate grasslands (C3) are higher than the rough tropical (C4) vegetation dominant in the Cerrado, which exhibit high dry weight accumulations that are often of low nutritive value (Van Soest, 1994). In the cerrado of the Pantanal the phenological succession correspond with rainy, flood and dry seasons (Pinder, 1997). It will be interesting to obtain more data on TGS for different pampas deer populations to assess on the change on this variable related to the nutritional quality of the pastures.

Other factor that influences the grouping size is related with reproductive behavior. The female segregation observed and the reduction in the size of nursery groups around the birth season has explained changes in the median group size. Meanwhile, in the mating season we observed in Los Ajos population a change in the conformation of the mixed-sex groups with larger proportions of this kind of groups. Similar observations were performed by Lacerda (2008).

Another analyzed factor was the available pasture in areas shared with livestock. For mixed-sex groups our data showed the major size on feeding groups was on winter in which was available ray grass pasture for cattle.

Thus, based on our results, pampas deer groups' structure and dynamics depend both on seasonal variation and in the requirements of individuals based on their sex and reproductive status. Then, in this population individuals associations pattern are link with the individual's optimal efficiency (fitness) (Krause \& Ruxton, 2002).

\section{Sexual aggregation-segregation}

Several authors propose that segregation between the sexes occurs in sexually dimorphic species because the difference in body size between adult males and adult females entails different feeding needs, "forage-selection hypotheses" (Clutton-Brock et al., 1982, Illius \& Gordon, 1987, Ruckstuhl, 1998, Barboza \& Bowyer, 2000, Yearsley \& Javier Pérez-Barbería, 2005). We observed a sexual aggregation-segregation pattern limited to a very specific reproductive and physiological moment (Figure 3). Pampas deer exhibits a low level of polygyny $(0.61$ O : $:$ ), and little sexual dimorphism in body size, the body mass of adult males being approximately 1.17 times that of adult females (González et al., 2010). The existence of a pattern of spatial segregation associated with sexual segregation could be linked to the "predation risk hypothesis" (Ruckstuhl \& Neuhaus, 2000), with females with small fawns staying in safer habitats while males choose for better quality pastures to meet their nutritional requirements during antler development, but it is necessary to deeper analysis on spatial segregation and pasture quality in order to have more categorical conclusions. 


\section{Conservation implications}

Pampas deer in Los Ajos occur exclusively in agroecosystems within several ranches on a RAMSAR Biosphere Reserve. This remaining population of the pampas deer has a critical size, which showed significant variations along the years. From a management perspective the PVA showed the populations has the intrinsic potential to survive being important to assure and increase the habitat available to guarantee the expansion and persistence in the future years.

\section{Competing interests}

The authors declare that they have no competing interests.

\section{Authors' contributions}

The fieldwork was conducted by MC and SG as part of MC's Ph.D. project and SG's CSIC (UdelaR) project. MC analyzed the data and led the writing with assistance from SG. Both authors read and approved the final manuscript.

\section{Acknowledgments}

Part of this research was supported by Comisión Sectorial de Investigación Científica (CSIC), Proyecto Dinámica Demográfica y Genética del Venado de Campo en el Uruguay, Programa de Desarrollo de Ciencias Básicas (PEDECIBA), MGAP-PPR, ANII from Uruguay, Wildlife Trust Alliance, Whitley Award Fund For Nature and Kilverstone Wildlife Charitable Trust. Special thanks to landowners families Arrarte and Etcheverry. Dr William Mc. Shea, who provided helpful comments that improved the quality of this manuscript.

\section{Received: 11 March 2013 Accepted: 17 May 2013}

Published: 10 June 2013

\section{References}

Barboza PS, Bowyer RT (2000) Sexual segregation in dimorphic deer: a new gastrocentric hypothesis. J Mammal 81:473-489

Bonenfant C, Gaillard JM, Loison A, Klein F (2003) Sex-ratio variation and reproductive costs in relation to density in a forest-dwelling population of red deer (Cervus elaphus). Behav Ecol 14:862-869

Bonenfant C, Gaillard JM, Dray S, Loison A, Royer M, Chessel D (2007) Testing sexual segregation and aggregation: old ways are best. Ecology 88:3202-3208

Braga FG, Kuniyoshi YS (2010) Estimativas de parâmetros populacionais e demográficos de Ozotoceros bezoarticus (Artiodactyla, Cervidae) em Piraí do Sul, Paraná, sul do Brasil. Iheringia Ser Zool 100:105-110

Cabrera A (1943) Sobre la sistemática del venado y su variación individual y geográfica. Revista del Museo de La Plata (ns), Sec Zool 18:5-41

Cabrera A, Yepes J, Wiedner CC (1940) Mamíferos sud-americanos: (vida, costumbres y descripción). Compañia Argentina de Editores, Buenos Aires

Caughley G (1964) Social organization and daily activity of the red kangaroo and the grey kangaroo. J Mammal 45:429-436

Clutton-Brock TH, Lukas D (2012) The evolution of social philopatry and dispersal in female mammals. Mol Ecol 21:472-492

Clutton-Brock TH, Guinness FE, Albon SD (1982) Red deer: behavior and ecology of two sexes. University of Chicago Press, Chicago

Cosse M, González S, Gimenez-Dixon M (2009) Feeding ecology of Ozotoceros bezoarticus: conservation implications in Uruguay. Iheringia Ser Zool 99:158-164

Coulon A, Cosson JF, Morellet N, Angibault J-M, Cargnelutti B, Galan M, Aulagnier $\mathrm{S}$, Hewison AJM (2006) Dispersal is not female biased in a resource-defence mating ungulate, the European roe deer. P Roy Soc B-Biol Sci 273:341-348

Dellafiore C, Demaría M, Maceira N, Bucher E (2003) Distribution and abundance of the pampas deer in San Luis province, Argentina. Mastozoología Neotropical 10:11-47

Development Core Team R (2009) R: A language and environment for statistical computing. R Foundation for Statistical Computing, Vienna, Austria

Dubost G (1970) L'organisation spatiale et sociale de Muntiacus reevesi Ogilby 1839 en semi-liberté. Mammalia 34:331-355

Eisenberg JF (2000) The contemporary Cervidae of Central and South America. In: Vrba ES, Schaller GB (eds) Antelopes, deer, and relatives: fossil record, behavioral ecology, systematics, and conservation. Yale University Press, New Haven, pp 189-202
Emlen ST, Oring LW (1977) Ecology, sexual selection, and the evolution of mating systems. Science 197:215-223

Fitzroy R, Darwin C (1839) Narrative of the surveying voyages of his majesty's ships adventure and beagle between the years 1826 and 1836 describing their examination of the southern shores of south America and the Beagles circumnavigation of the globes. Henry Colburn, London

Fonseca GAB, Mittermeier RA, Cavalcanti RB, Mittermeier CG (1999) Brazilian Cerrado. In: Mittermeier RA, Myers N, Mittermeier CG, Gil R (eds) Hotspots: Earth's biologically richest and most endangered terrestrial ecoregions. CEMEX, SA, Agrupación Sierra Madre, SC, Chicago, pp 149-155

Giménez Dixon M (1991) Estimación de parámetros poblacionales del venado de las Pampas [Ozotoceros bezoarticus celer, Cabr., 1943-Cervidae-] en la costa de la bahía de Samborombón [prov. Buenos Aires] a partir de datos obtenidos mediante censos aéreos, Facultad de Ciencias Naturales y Museo. Universidad Nacional de La Plata, La Plata, p 116

González S, Duarte JMB (2003) Emergency pampas deer capture in Uruguay. DSG News 18:16-17

González S, Maldonado JE, Leonard JA, Vilà C, Duarte JMB, Merino M, BrumZorrilla N, Wayne RK (1998) Conservation genetics of the endangered Pampas deer (Ozotoceros bezoarticus). Mol Ecol 7:47-56

González S, Álvarez-Valin F, Maldonado JE (2002) Morphometric differentiation of endangered pampas deer (Ozotoceros bezoarticus), with description of new subspecies from Uruguay. J Mammal 83:1127-1140

González S, Cosse M, Góss Braga F, Vila AR, Merino ML, Dellafiore C, Cartes JL, Maffei L, Gimenez Dixon M (2010) Pampas deer Ozotoceros bezoarticus (Linnaeus 1758). In: Duarte JMB, Gonzalez S (eds) Neotropical Cervidology: biology and medicine of Latin American deer. Funep/IUCN, Jaboticabal, pp 119-132

Hofmann RR (1989) Evolutionary steps of ecophysiological adaptation and diversification of ruminants: a comparative view of their digestive system. Oecologia 78:443-457

Illius A, Gordon I (1987) The allometry of food intake in grazing ruminants. J Anim Ecol 56:989-999

Jackson JE, Giulietti J (1988) The food habits of Pampas deer Ozotoceros bezoarticus celer in relation to its conservation in a relict natural grassland in Argentina. Biol Conserv 45:1-10

Jackson JE, Langguth A (1987) Ecology and status of the pampas deer in the Argentinian pampas and Uruguay. In: Wemmer C (ed) Biology and management of the Cervidae. Smithsonian Institute, Washington, DC, pp 402-409

Jackson J, Landa P, Langguth A (1980) Pampas deer in Uruguay. Oryx 15:267-272

Jarman PJ (1974) The social Organization of antelope in relation to their ecology. Behaviour 48:215-267

Jeschke J, Kokko H (2009) The roles of body size and phylogeny in fast and slow life histories. Evol Ecol 23:867-878

Kaji K, Takahashi H, Tanaka J, Tanaka Y (2005) Variation in the herd composition counts of sika deer. Popul Ecol 47:53-59

Kirkman TW (1996) Statistics to use. http://www.physics.csbsju.edu/stats/ exact_NROW_NCOLUMN_form.html (04-09-2012)

Krause J, Ruxton GD (2002) Living in groups. Oxford University Press, Oxford

Kruuk LE, Clutton-Brock TH, Albon SD, Pemberton JM, Guinness FE (1999) Population density affects sex ratio variation in red deer. Nature 399:459-461

Lacerda ACR (2008) Ecologia e estrutura social do veado-campeiro (Ozotoceros bezoarticus) no Pantanal, Instituto de Ciências Biológicas: 194. Universidade de Brasília, Brasília

Lacy RC, Borbat M et al (2009) Vortex: A stochastic simulation of the extinction process. Version 9.95. Chicago Zoological Society, http://pw1.netcom.com/ rlacy/ vortex.html (06-03-2013)

Leeuwenberg F, Lara Resende S (1994) Ecologia de cervídeos na Reserva Ecológica do IBGE-DF: manejo e densidade de populações. Cad Geoc 11:89-95

Linnaeus C (1758) Systema naturae per regna tria naturae: secundum classes, ordines, genera, species, cum characteribus, differentiis, synonymis, locis (in Latin), 10th edn. Laurentius Salvius, Stockholm

Loe LE, Mysterud A, Veiberg VR, Langvatn R (2009) Negative density-dependent emigration of males in an increasing red deer population. P Roy Soc B-Biol Sci 276:2581-2587

Loison A, Festa-Bianchet M, Gaillard J-M, Jorgenson JT, Jullien J-M (1999) Agespecific survival in five populations of ungulates: evidence of senescence. Ecology 80:2539-2554

Merino M, Beccaceci M (1999) Ozotoceros bezoarticus (Artiodactyla, Cervidae) en Corrientes, Argentina: distribución, población y conservación. Iheringia, Ser Zool 87:87-92 

Emalsa, Madrid

Miura S (1984) Social behavior and territoriality in male sika deer (Cervus nippon Temminck 1838) during the rut. Z Tierpsychol 64:33-73

Moore D (2001) Aspects of the behavior, ecology and conservation of the Pampas Deer, College of Environmental Science and Forestry: 282. State University of New York Syracuse, New York

Morrison ML, Marcot BG, Mannan RW (2006) Wildlife-habitat relationships concepts and applications. Island Press, Washington

Mourão G, Coutinho M, Mauro R, Campos Z, Tomás W, Magnusson W (2000) Aerial surveys of caiman, marsh deer and pampas deer in the Pantanal Wetland of Brazil. Biol Conserv 92:175-183

Netto NT, Coutinho-Netto CRM, Costa MJRP, Bon R (2000) Grouping patterns of Pampas deer (Ozotoceros bezoarticus) in the Emas National Park Brazil. Revista de Etologia 2:85-94

Pereira RJG, Duarte JMB, Negrão JA (2005) Seasonal changes in fecal testosterone concentrations and their relationship to the reproductive behavior, antler cycle and grouping patterns in free-ranging male Pampas deer (Ozotoceros bezoarticus bezoarticus). Theriogenology 63:2113-2125

Pereira RJG, Duarte JMB, Negrão JA (2006) Effects of environmental conditions, human activity, reproduction, antler cycle and grouping on fecal glucocorticoids of free-ranging Pampas deer stags (Ozotoceros bezoarticus bezoarticus). Horm Behav 49:114-122

Pérez Carusi LC, Beade MS, Miñarro F, Vila AR, Giménez-Dixon M, Bilenca DN (2009) Relaciones espaciales y numéricas entre venados de las pampas (Ozotoceros bezoarticus celer) y chanchos cimarrones (Sus scrofa) en el Refugio de Vida Silvestre Bahía Samborombón. Argentina Ecol Austral 19:63-71

Pinder L (1997) Niche overlap among brown brocket deer, pampas deer, and cattle in the Pantanal of Brazil. Ph.D. dissertation, University of Florida, Gainsville

Putman R (1988) The natural history of deer. Comstock Pub. Associates, Ithaca, N.Y

Putman R, Flueck WT (2011) Intraspecific variation in biology and ecology of deer: magnitude and causation. Anim Prod Sci 51:277-291

Redford K (1987) The pampas deer (Ozotoceros bezoarticus) in central Brazil. In: Wemmer C (ed) Biology and management of the Cervidae. Smithsonian Institute, Washington, DC, pp 410-414

Reznick D, Bryant MJ, Bashey F (2002) r- and K-Selection Revisited: The Role of Population Regulation in Life-History Evolution. Ecology 83:1509-1520

Rodrigues FHG, Monteiro-Filho ELA (1999) Feeding behaviour of the pampas deer: a grazer or a browser? DSG News 15:12-13

Ruckstuhl KE (1998) Foraging behaviour and sexual segregation in bighorn sheep. Anim Behav 56:99-106

Ruckstuhl KE (2007) Sexual segregation in vertebrates: proximate and ultimate causes. Integr Comp Biol 47:245-257

Ruckstuhl KE, Neuhaus P (2000) Sexual segregation in ungulates: a new approach. Behaviour 137:361-377

Schaller GB, Duplaix-Hall N (1975) Notes on the large mammals of the Parque Nacional das Emas, Brazil. Proc, no 004370/75

Ungerfeld R, Gonzalez-Pensado S, Villagran M, Olazabal D, Bielli A, Perez W (2008) Reproductive biology of the pampas deer (Ozotoceros bezoarticus): A review. Acta Vet Scand 50:1

Van Soest PJ (1994) Nutritional ecology of the ruminant. Comstock Pub, Ithaca

Vanpé C, Morellet N, Kjellander P, Goulard M, Liberg O, Hewison AJM (2009)

Access to mates in a territorial ungulate is determined by the size of a male's territory, but not by its habitat quality. J Anim Ecol 78:42-51

Wahlström LK (1994) The significance of male-male aggression for yearling dispersal in roe deer (Capreolus capreolus). Behav Ecol Sociobiol 35:409-412

Yearsley JM, Javier Pérez-Barbería F (2005) Does the activity budget hypothesis explain sexual segregation in ungulates? Anim Behav 69:257-267

Zar JH (1999) Biostatistical analysis. Upper Saddle River, New Jersey: Prentice-Hall

doi:10.1186/2193-1801-2-259

Cite this article as: Cosse and González: Demographic characterization and social patterns of the Neotropical pampas deer. SpringerPlus 2013 2:259.

\section{Submit your manuscript to a SpringerOpen ${ }^{\odot}$ journal and benefit from:}

- Convenient online submission

- Rigorous peer review

- Immediate publication on acceptance

- Open access: articles freely available online

- High visibility within the field

- Retaining the copyright to your article

Submit your next manuscript at $\gg$ springeropen.com 